\title{
SEISMIC ANALYSIS OF LOW TO MEDIUM RISE BUILDING FOR BASE ISOLATION
}

\author{
H.P. Santhosh ${ }^{1}$, K.S. Manjunath ${ }^{2}$, K. Sathish Kumar ${ }^{3}$ \\ ${ }^{1}$ M-Tech Student, ${ }^{2}$ Associate Professor, Department of Civil Engineering, MCE Hasana, Karnataka-573201 \\ ${ }^{3}$ Senior Principal Scientist, ASTaR Laboratory, CSIR-SERC, CSIR Campus, Chennai-600113, \\ hpsanthosh@gmail.com,kattihallimanju@yahoomail.com,ksk@serc.res.in
}

\begin{abstract}
Seismic isolation is an alternative to conventional design methods for dealing with earthquake loadings in relatively high frequency structures, especially in low to medium rise buildings. One of the goals of seismic isolation is to shift the fundamental frequency of the structure away from the dominant frequencies of seismic excitations and fundamental frequency of the fixed base structure. This innovative design approach aims mainly at the isolation of a structure from the supporting ground, usually in the horizontal directions in order to reduce the transmission of the earthquake motion to the super structure.

In this paper seismic analysis performed for a low to medium rise fixed base building and it was observed that the fundamental time period of the fixed system are typically in the resonance range of $0.1 \mathrm{sec}$. to $2.0 \mathrm{sec}$. This results in amplification of the ground acceleration causing severe damage to structures and their contents. To avoid such a situation, the period must be lengthened, by increasing the flexibility of the structure by introducing seismic base isolators between the foundation and super structures. A six storey structure under both fixed base and seismically isolated boundary conditions is studied to demonstrate the effectiveness of seismic isolation. The comparative result shows that maximum floor acceleration, inter-storey drifts and storey shear forces are reduced substantially for seismically isolated structure.
\end{abstract}

Keywords: Seismic base isolation, Seismic resistant design, Lead rubber bearings, Response spectrum analysis, Time period.

\section{INTRODUCTION}

A seismically isolated structure has a fundamental frequency that is much lower than the fundamental frequency of the corresponding fixed supported structure and the predominant frequencies of a typical earthquake. This is achieved by mounting the structures on a set of isolators that provides low horizontal stiffness and consequently, shifts the fundamental frequencies of the structures to much lower values. A seismically isolated structure experiences reduced seismic forces and accelerations and moves essentially as a rigid body, preventing damage due to deformations.

In the base isolation strategy, it is possible to obtain a considerable reduction of large displacements attained at the base level as a consequence of the energy dissipation due to damping and hysteretic properties of isolation device. Many buildings have been constructed on various types of seismic bearings, and such structures have shown superior performance during earthquakes [1].

\subsection{Historical Background}

A purely sliding isolation system is the earliest and the simplest isolation system proposed in 1909 by Johannes Avetican Calantarients, a medical doctor in England [2]. $\mathrm{He}$ suggested separating the structure from the foundation by a layer of talc; isolation system reduces accelerations in the isolated building at the expense of large relative displacements between the building and the foundation. Calantarient's base isolation system using a layer of talc as the isolation medium shown in Fig.1 


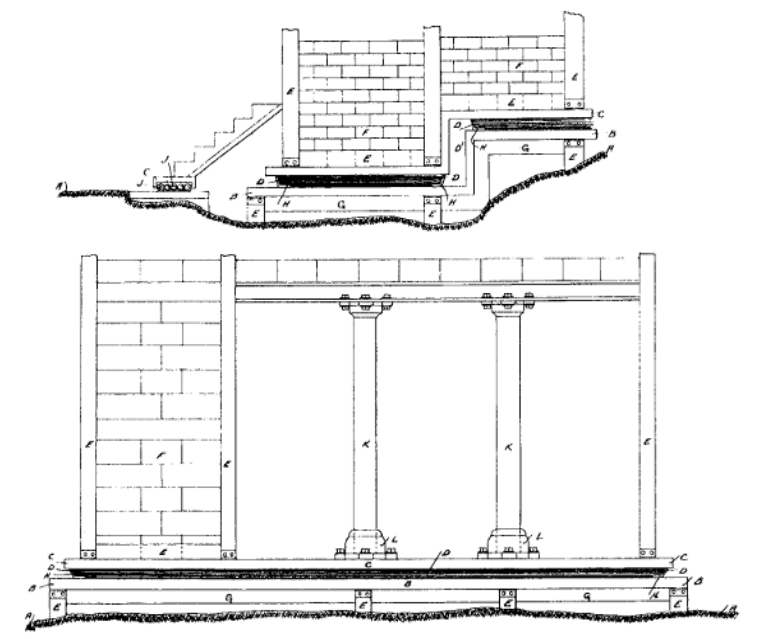

Fig.1 Calantarient's base isolation system using a layer of talc as the isolation medium

\subsection{Seismic Base Isolation Using Sand}

The largest is a four storey dormitory building constructed for the Earthquake Strong Motion Observatory in Beijing in which the sliding surface is a layer of specially selected sand between terrazzo plates that are located above the foundation and under the walls at the ground floor level [2].

\subsection{New Bhuj Hospital with Base Isolation}

\section{Technology}

The 300-bed new Bhuj hospital replaces the building that claimed 176 lives when it collapsed during the January 2001 Gujarat earthquake. This is the first seismically isolated building in India fitted with laminated rubber bearings. With this technology, the building can sway for $35 \mathrm{~cm}$ in the two horizontal directions for an earthquake measuring eight on the Richter scale.

\section{CONCEPT OF SEISMIC ISOLATION}

The isolation system decouples the structure from the horizontal components of the ground motion by imposing structural elements with low horizontal stiffness between the structure and foundation. The superstructure essentially acts like a rigid body with reduced inter storey drifts, thus mitigating the subsequent seismic damage. Fig. 2 shows the mechanisms of base isolation subjected to ground motion. The isolation reduces the fundamental frequency of the structure from its fixed base frequency and thus shifts the position of the structure in the spectrum from the peak-plateau region to the lower regions. Also, it brings additional damping due to the increased damping introduced at the base level, and thus further reduction in the spectral acceleration is achieved.

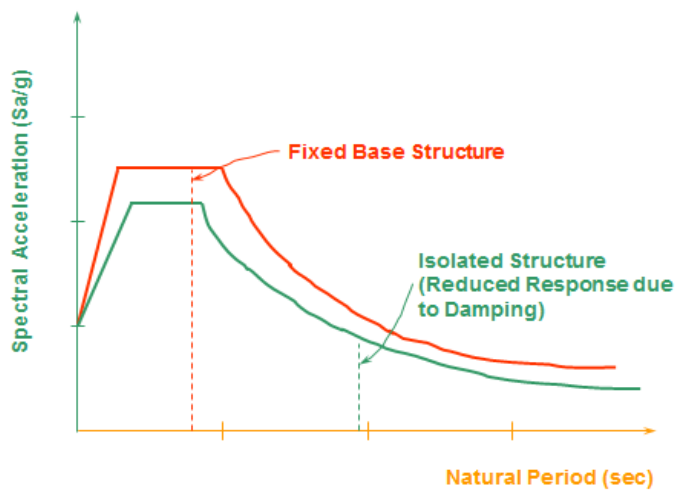

Fig. 2 Mechanism of base isolation

\section{1 Classification of Seismic Isolation Systems}

Seismic Isolation systems are generally classified as,

- Elastomer based systems

- $\quad$ Sliding / Friction based systems

- $\quad$ Spring type systems

- $\quad$ Sleeved - Pile system

- Rocking systems

\section{ISOLATION SYSTEM BASED ON LEAD RUBBER BEARING}

Lead Rubber Bearings (LRB) are seismic isolators made up of alternate layers of steel laminates and hot vulcanized rubber with a cylindrical central lead core. The energy dissipation provided by the lead core, through yielding, allows to achieve an equivalent viscous damping coefficient up to about $30 \%$, i.e. two times that of high damping elastomeric isolators[4]. The advantage claimed in this type of bearing is that the unnecessary movement of the structure under low load levels due to wind and low intensity earthquake is prevented on account of the high elastic stiffness of the plug. At higher loads, the plug yields and the shear stiffness of the system is significantly reduced providing the desired period shift characteristics and energy dissipation mechanism. Through the high energy dissipation capacity, it is possible to reduce the horizontal displacement, in comparison with that of an isolation system with the same equivalent stiffness but lower energy dissipation capacity. Usually, they are circular in shape but can also be fabricated in square sections; they can also be fabricated with more than one lead core.

\subsection{Mechanical Characteristics of Lead Rubber}

\section{Isolators}

The total horizontal and vertical stiffness of the rubber isolators is computed using single degree of freedom system equation, shown in the Table 1[5]. 
Table 1 Mechanical characteristic of lead rubber isolators

\begin{tabular}{|c|c|c|c|}
\hline Horizontal stiffness $(\mathrm{KH})$ & $K_{H}=\frac{G A}{t_{r}}$ & $\begin{array}{l}1125 \\
\mathrm{kN} / \mathrm{m}\end{array}$ & $\begin{array}{l}\text { Where, } \\
\mathrm{G}=\text { Shear modulus }=1.06 \mathrm{MN} / \mathrm{m} 2 \text {, } \\
\mathrm{A}=\text { Effective area of individual rubber }\end{array}$ \\
\hline Vertical stiffness(KV) & $K_{V}=\frac{E_{c} A}{t_{r}}$ & $2700 \mathrm{kN} / \mathrm{m}$ & $\begin{array}{l}\text { layers, } \\
\text { tr= Total height of the rubber layer, } \\
\text { EC=Compression modulus. }\end{array}$ \\
\hline Area of Lead AP & $A_{p}=\frac{Q_{D}}{f_{p y}}$ & $84.33 \mathrm{~cm} 2$ & $\begin{array}{l}\text { QD=Short term yield force, } \\
\text { fPY=Yield strength of lead core }=8.82 \\
\text { MN/M2, }\end{array}$ \\
\hline $\begin{array}{l}\text { Total height of rubber } \\
\text { layers tr }\end{array}$ & $\operatorname{tr}=\mathrm{DD} / \square \max$ & $0.42 \mathrm{~m}$ & $\begin{array}{l}\mathrm{DD}=\text { Design displacement, } \\
\square \max =\text { Maximum shear strain }\end{array}$ \\
\hline $\begin{array}{l}\text { Single layer thickness of } \\
\text { rubber layer ' } t \text { ' }\end{array}$ & $\mathrm{t}=\frac{\mathrm{d}}{4 \mathrm{~S}}$ & $\begin{array}{l}1.375 \mathrm{~cm} \\
\text { Say } 1.5 \mathrm{~cm}\end{array}$ & $\begin{array}{l}S=\text { shape factor }=20, \\
d=\text { lead core } \text { diameter }=11 \mathrm{~cm} .\end{array}$ \\
\hline Steel plate thickness tS & $\mathrm{t}_{\mathrm{S}}=\frac{2(0.01+0.01) \mathrm{P}_{\mathrm{DL}+\mathrm{LL}}}{\mathrm{A}_{\mathrm{re}} \cdot \mathrm{F}_{\mathrm{S}}}$ & $\begin{array}{l}1.77 \mathrm{~mm} \\
\text { Say } 2 \mathrm{~mm}\end{array}$ & $\begin{array}{l}\text { Are=Reduced area, } \\
F s=\text { for steel } 0.6 \mathrm{Fy}\end{array}$ \\
\hline $\begin{array}{l}\text { Total height ' } h \text { ' of the } \\
\text { bearing }\end{array}$ & $\mathrm{h}=\mathrm{tr}+41 \mathrm{xts}+2 \times 5 \mathrm{~cm}$ & $60.2 \mathrm{~cm}$ & $\begin{array}{l}\text { Remarks, } \\
\text { Assuming the thickness of the top and } \\
\text { bottom cover plates both to be } 5 \mathrm{~cm} \text {. }\end{array}$ \\
\hline
\end{tabular}

\section{DYNAMIC ANALYSIS}

Dynamic analysis using STAAD Pro software is performed to obtain the design seismic force, and its distribution to different levels along the height of the building and to the various lateral load resisting elements [3].

\subsection{Response Spectrum Analysis}

In the present study response spectrum method of analysis was performed using the design spectrum specified, or by a sitespecific design spectrum mentioned. Response spectra for 5 percent damping IS 1893:2002 are shown in Fig.3 [6].

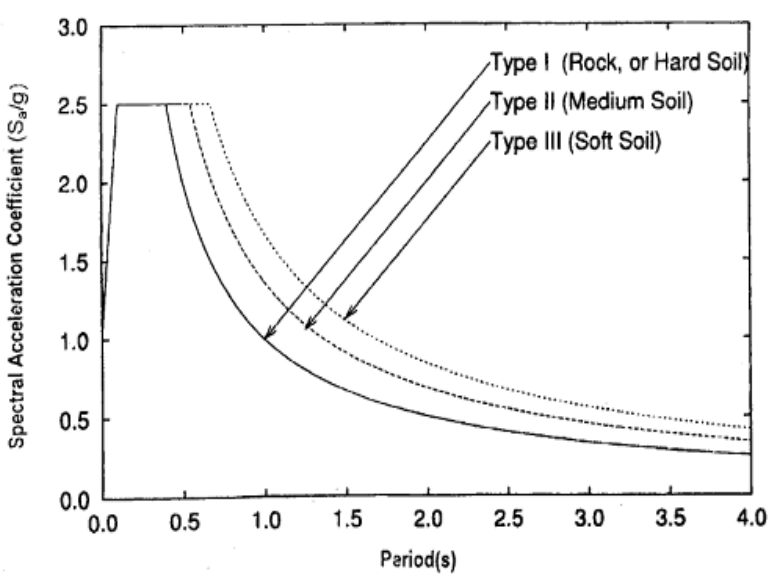

Fig.3 Response spectra for 5 percent damping IS 1893: 2002

\subsection{Problem Definition}

The six storey building for a commercial complex is considered to be located in seismic zone III on a site with medium soil. The selected building was designed for seismic loads as per IS 1893(Part 1): 2002 [7]. 


\section{ANALYTICAL RESULTS}

Response spectrum analysis was performed for the selected fixed base building of different heights and for a fixed base and base isolated six storey building. The superstructure is assumed to be in elastic linear range. Isolator properties used in base isolated building are given in the Table 1 . The comparisons of time period, storey shear and Spectral acceleration are shown in Fig. 4 and Fig.5 respectively. The time period versus different storey heights is shown in Fig. 6.

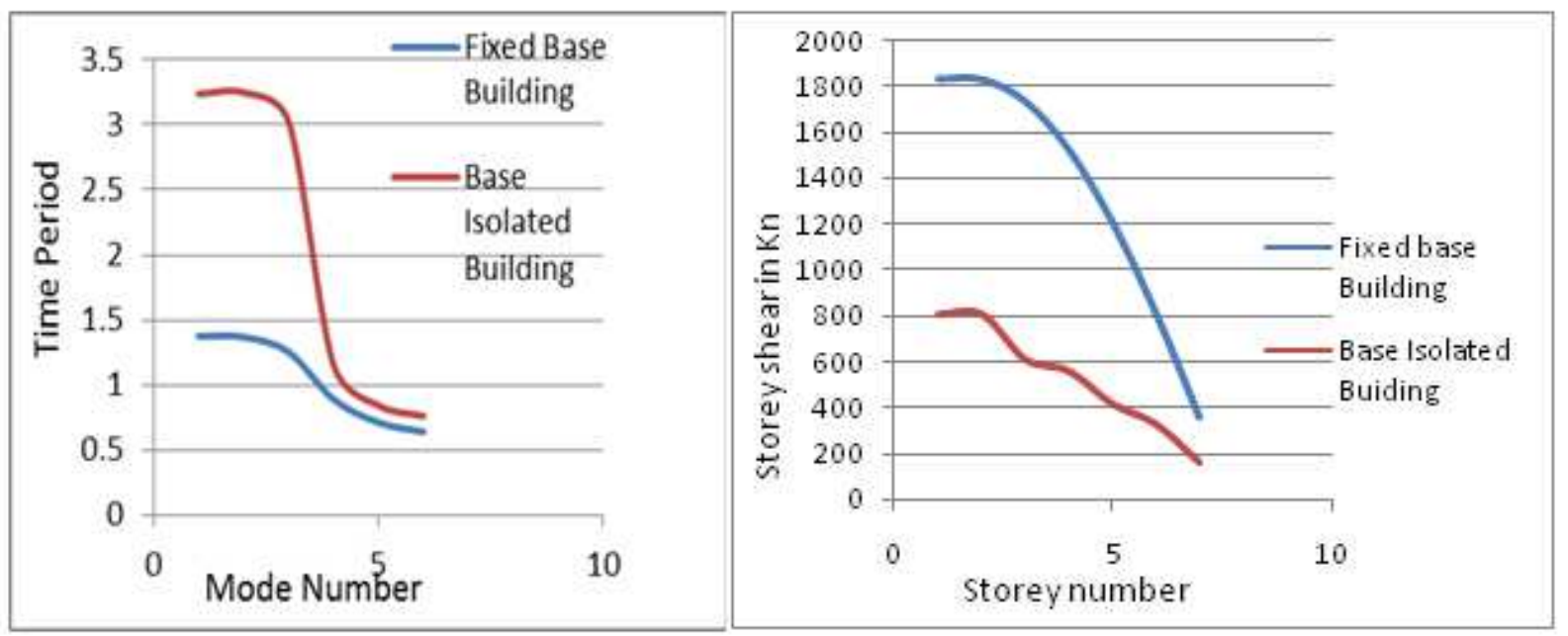

Fig.4 Comparison of Time period and Storey Shear for Fixed Base and Base Isolated building

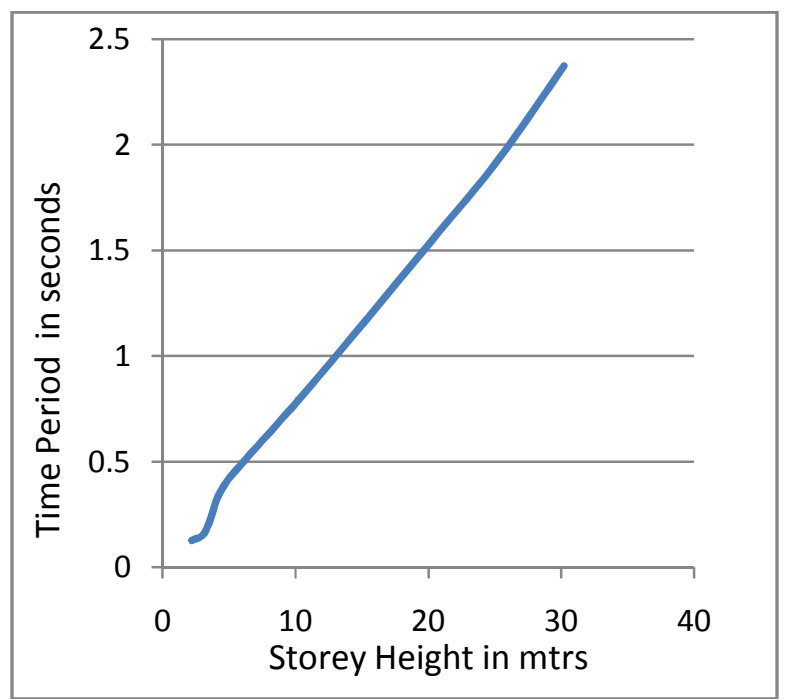

Fig. 5 Comparison of spectral acceleration for fixed base and base isolated building.

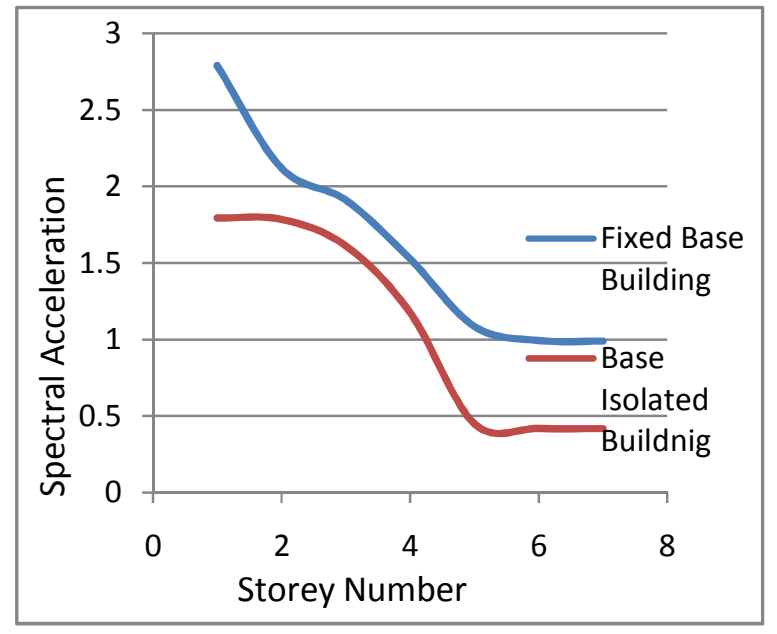

Fig. 6 Time Period versus Storey height for fixed base building.

\section{CONCLUSIONS}

In this paper seismic analysis performed for a selected low to medium rise fixed base building. It is observed that, the buildings height which lies in the range of $3 \mathrm{~m}$ to $25 \mathrm{~m}$ are of fundamental time period typically found in the resonance 
range of $0.1 \mathrm{sec}$. to $2.0 \mathrm{sec}$, which constitute the overwhelming majority of buildings worldwide. This results shows that base isolation is best suitable for low to medium rise buildings.

A six storey structure under both fixed supported and seismically isolated boundary conditions is studied to demonstrate the effectiveness of seismic isolation. The analytical results show that maximum floor acceleration, interstorey drifts and storey shear forces are reduced substantially for seismically isolated structure.

\section{REFERENCES}

[1] Petros Komodromos (2000) Seismic Isolation for Earthquake-Resistant Structures, WIT press, Southampton, Boston

[2] Farzad Naeim and James M. Kelly (1999) Design of Seismic Isolated Structures from Theory to Practice, John Wiley \& Sons, Inc., New York

[3] T.K. Datta (2010) Seismic Analysis of Structures, John Wiley \& Sons (Asia) Pte Ltd.

[4] Trevor E. Kelly, R. Ivan Skinner and Bill (W.H.) Robinson (2010) Seismic Isolation for Designers and Structural Engineers

[5] Wai-Fah Chen and Charles Scawthorn (2003) Earthquake Engineering Handbook, CRC PRESS, London.

[6] IS: 1893 (part 1): 2002 Criteria for Earthquake Resistant Design of Structures, BIS, New Delhi, India.

[7] Dr. H. J. Shah and Dr. Sudhir K Jain, (2009) Design Example of a Six Storey Building, Department of Applied Mechanics M. S. University of Baroda, Vadodara. 